\title{
Uma Epopeia Goiana
}

\author{
An Epopea of Goias \\ Una Epopeya de Goias
}

\author{
Marcelo Lapuente Mabl ${ }^{1 *}$ \\ ${ }^{1}$ Universidade Federal de Uberlândia, Uberlândia / MG - Brasil
}

Silva, Sandro Dutra. No Oeste, a terra e o céu - a expansão da fronteira agrícola no Brasil Central. Rio de Janeiro: Mauad X, 2017.

A permanência da mítica bandeirante, tantas vezes reinventada ao longo da história nacional, é o fio condutor desta história do desbravamento do Brasil Central, estudada agora por Sandro Dutra e Silva em seu livro No Oeste, a terra e o céu, publicado pela editora Mauad X. Resultado de uma intensa trajetória de pesquisa, com andanças tanto no Brasil quanto no exterior, o trabalho traz uma reflexão, fundamentada em uma abrangente compilação de fontes primárias, sobre o quanto as diversas imagens associadas aos bandeirantes paulistas contribuíram para a expansão agrícola em direção ao estado de Goiás, na primeira metade do século XX. Para tanto, o autor estabelece um diálogo profícuo com a história ambiental, o que lhe permite acessar os íntimos meandros das forças simbólicas presentes no processo de ocupação econômica do Oeste sem perder do horizonte as complexas interaçōes entre homem, sociedade e natureza, especialmente durante o período varguista.

Além disso, cabe ressaltar também a proximidade do autor com a historiografia norte-americana, principalmente com aquela preocupada em avaliar criticamente ou, melhor dizendo, realinhar o conceito de fronteira aos novos tempos. Desde a tese pioneira de F. J. Turner, apresentada em Chicago em 1893, muito se escreveu sobre a presença desse espaço que extrapola a realidade material - com sua existência tangível -, permitindo uma imersão no universo mítico e simbólico que o conceito abarca. Desnecessário falar do quanto a tese de Turner foi importante e influente, mas também limitadora e restritiva, principalmente quando se pensa em seus desdobramentos e aplicaçôes à realidade brasileira. De todo modo, a fronteira imaginada por Sandro Dutra e Silva não se entrega

DOI: http://dx.doi.org/10.1590/2237-101X02104516

Resenha recebida em 6 de julho de 2019 e aceita para publicação em 24 de outubro de 2019.

* Professor da Universidade Federal de Uberlândia / Faculdade de Artes, Filosofia e Ciências Sociais / Instituto de História, Uberlândia / MG - Brasil. E-mails: mlmhistor@hotmail.com / mlmahl@ufu.br. ORCID: https://orcid.org/0000-0001-6749-7654. 
à facilidade da análise nem à simplificação, revelando, ao contrário, um espaço onde as açóes políticas e os movimentos e interesses do capital acabam por criar um ambiente de agitaçóes, rupturas, descontinuidades e, por que não dizer, decepçóes, incorporadas e reveladas não somente nos corpos e nas práticas dos sujeitos desta hinterland, mas também ao próprio meio físico. $\mathrm{O}$ quadro que nasce daí interessa pela sua crueza. Não se lê impunemente o relato sobre o pai que, em meio à sua condição de extrema pobreza, sugere dar o próprio filho a uma estupefata forasteira. $\mathrm{O}$ autor nos mostra neste e em outros momentos as contradiçóes inerentes à terra prometida.

O livro se estrutura em duas partes distintas que se complementam. Na primeira, dividida em seis capítulos, encontra-se uma grande história do território de Goiás, desde os primórdios da colonização até a sua transformação em zona especial de fronteira durante o governo Vargas. Parte-se então do geral para o específico: da grande área despovoada do século XVI vemos surgir uma nova sociedade construída no encalço da atividade pecuária e agrícola, onde populaçóes de diferentes regióes do país e do estrangeiro, em fluxos nem sempre contínuos, buscam então se adaptar às singulares realidades ambientais do Brasil Central. Na segunda parte, três capítulos apresentam uma reflexão sobre os núcleos urbanos na região da fronteira no Brasil Central, com especial atenção para a cidade de Goiânia e para a recém-fundada Colônia Agrícola Nacional de Goiás. Uma leitura mais pormenorizada leva à seguinte ordem:
Os dois primeiros capítulos percorrem as diferentes franjas de ocupação e povoamento no Brasil Central, desde o século XVIII, com destaque para as frentes abertas pela mineração e pela crescente atividade agropecuária. $\mathrm{O}$ estado do Goiás recebe em toda a obra uma atenção mais específica, principalmente no que se refere aos seus fluxos populacionais, impulsionados pelas expectativas de enriquecimento em terras abundantes, convertendo a região, nas décadas de 1930 e 1940, em grande vitrine dos projetos de colonização impulsionados pelo governo federal. Todo esse fluxo de pessoas e capitais foi acompanhado com especial interesse pela burocracia getulista, que não poupou esforços para impulsionar e controlar, na medida do possível, o desenvolvimento do sertão por meio da criação, em 1941, da Colônia Agrícola Nacional de Goiás; tema que retornará em vários outros momentos do livro. No capítulo terceiro, o autor aborda o nível simbólico da "Marcha para Oeste", especificamente o processo de ressignificação do mito bandeirante. Aí, em especial, percebe-se claramente como a figura do paulista intrépido, que já havia servido de exemplo para a colonização de outras regiôes do Brasil, ao final do século XIX, continuava oferecendo um modelo eficaz para esses novos esforços colonizadores.

Os capítulos quatro e cinco são os que mais se aproximam dos pressupostos já consolidados da história ambiental, com a definição ecológica, ou melhor, biogeográfica do sertão goiano, e os impactos que toda a transformação econômica e social da região causaram nas florestas tropicais e nos cam- 
pos cerrados. Ressalta-se aí a escolha do autor em utilizar não somente a bibliografia específica sobre os biomas brasileiros, trazida principalmente da geografia, mas também de memórias que descreveram, em momentos distintos, os aspectos naturais desse vasto território. Talvez falte aí, na utilização das fontes memorialísticas, uma discussão mais pormenorizada sobre o quanto esses relatos, que parecem dialogar com a tradição romântica na descrição das paisagens naturais brasileiras, foram modificados pelos olhares cheios de idealizações e nostalgia. De todo modo, é fato que as transformaçóes ambientais que são consequência direta dos movimentos das franjas pioneiras deixaram uma marca indelével no mundo natural; modificaçóes minuciosamente apresentadas em todo o livro.

O capítulo seis aponta mais especificamente para Anápolis, em cuja área de influência foi instalada a Colônia Agrícola Nacional de Goiás. Lemos então sobre a importância da chegada da ferrovia para a transformação dessa cidade, convertendo-a em uma pujante zona de povoamento, atraindo migrantes de todo o país, além de estrangeiros de várias nacionalidades. Nesse momento Sandro Dutra nos relata a curiosa chegada à regiâo de muitos cidadãos norte-americanos, portando seu poder financeiro e inúmeros sonhos de progresso que agitaram a vida econômica e social goiana, com direito até a presença inusitada de astros de Hollywood imersos nesse ambiente pioneiro. Entretanto, essa experiência parece ter deixado também saldos negativos, com dívidas não liquidadas e uma certa desconfiança so- bre os verdadeiros interesses dos simpáticos estadunidenses. Não seria a política de boa vizinhança, impulsionadas pelo governo de Franklin Roosevelt, um dos motivos dessa atenção, além das terras baratas e as possibilidades de especulação fundiária? A pergunta fica em aberto, mas não a percepçáo de que a construçáo de Goiás como uma terra de riquezas extrapolou, e muito, as fronteiras nacionais.

O capítulo sete retoma e expande a reflexão sobre a Colônia Agrícola Nacional de Goiás. O seu núcleo principal de colonização cortava uma zona rica em biodiversidade (as Matas de Sáo Patrício) para se assentar às margens do Rio das Almas. $\mathrm{O}$ autor nos mostra, talvez no momento mais importante e revelador do livro, as contradiçóes entre o que os colonos almejavam quando iam em direção à Colônia - o enriquecimento em uma zona pioneira -, e o que realmente se encontrava: conflitos fundiários, doenças, dificuldades financeiras, ou seja, uma série de expectativas frustradas, que revelam a grande distância entre as promessas institucionais e a sua limitada e fraturada execução. Isto se mostra de forma evidente também no capítulo oito, quando conhecemos a história de Barranca (atual Rialma), povoamento vizinho à Colônia Oficial (atual Ceres), que se forma à margem dos esforços estatais e que, a despeito do preconceito e da desconfiança, acaba por se tornar também uma zona que se expande e se constrói independentemente dos auspícios governamentais. Talvez seja essa capacidade de superação e de autodeterminação das populaçóes migrantes que definam melhor essas áreas de fronteira nos 
mais variados sertóes brasileiros. Assim, não resta dúvida que mesmo os excluídos e estigmatizados conseguiram romper as fronteiras físicas e simbólicas para ocupar, não sem esforço, o seu pedaço do paraíso, a despeito dos desejos sinuosos e obscuros do poder.

No derradeiro capítulo, Sandro Dutra nos oferece um panorama biográfico do engenheiro agrônomo Bernardo Sayão, que parece representar o próprio modelo ideal desse "novo bandeirante". Tendo ocupado vários cargos públicos, inclusive o de vice-governador de Goiás, morreu em um trágico acidente durante o final da construçấo da rodovia Belém-Brasília, em 1959. Alçado à condição de herói, principalmente pelas narrativas de exaltação da história goiana, Sayão é visto pelo autor como uma peça exemplar do poder das imagens e das representaçôes que constituíram um vetor fundamental no processo das transformaçôes pelas quais o Brasil Central passou ao longo do século XX.

$\mathrm{O}$ mote fundamental dessa epopeia Goiana - o mito bandeirante, que impulsiona a busca por esse novo Eldorado -, que sustentou a lógica da expansão agrícola nacional em outras regióes, como Sáo Paulo, Paraná e Minas Gerais, conforme demonstrou o geógrafo francês Pierre Monbeig (1984), em seu livro Pioneiros e fazendeiros de São Paulo, parece ter como singularidade os ecos de um profundo sentimento religioso, que Sandro Dutra e Silva inclui como componente fundamental no imaginário desses povoadores do Mato Grosso de Goiás. Uma esperança renovada constantemente pela terra sempre prometida, mas que tarda a se cumprir frente aos inúmeros passivos sociais e ambientais que foram deixados ao longo do processo de ocupação desse território de abundantes terras e infinito céu.

Por fim, o livro No Oeste, a terra e o céu - a expansão da fronteira agrícola no Brasil Central contribui náo só para o campo da história ambiental, como também para a própria história cultural, ao entrelaçar de modo convincente os conceitos de representação e imaginário às condiçôes materiais existentes no Brasil da primeira metade do século XX; problematizando essas duas instâncias que, estudadas em suas intrincadas relaçôes de causalidade e efeito, servem de amostra do que tem sido produzido atualmente por uma nova geração de pesquisadores brasileiros.

\section{Referências}

MONBEIG, Pierre. Pioneiros e fazendeiros de São Paulo. Trad. Ary França e Raul de Andrade e Silva. São Paulo: Hucitec/Polis, 1984.

SILVA, Sandro Dutra. No Oeste, a terra e o céu - a expansão da fronteira agrícola no Brasil Central. Rio de Janeiro: Mauad X, 2017. 